\title{
Interactive assistant tool for the evaluation of kinematic patterns and EMG signals in patients with a forearm injury
}

\section{Herramienta de asistente interactivo para la evaluación de patrones cinemáticos y señales EMG en pacientes con lesión del antebrazo}

\author{
JIMÉNEZ-GONZÁLEZ, Fernando C.†* \& TORRES-RAMÍREZ, Dulce Esperanza
}

Universidad Tecnológica de Ciudad Juárez.

ID $1^{\text {st }}$ Author: Fernando C., Jiménez-González / ORC ID: 0000-0002-4577-3408, CVU CONACYT ID: 443945

ID $1^{\text {st }}$ Coauthor: Dulce Esperanza, Torres-Ramírez / ORC ID: 0000-0001-8409-2691, Researcher ID Thomson: U-82372018, CVU CONACYT ID: 322126

DOI: $10.35429 / J T E N .2021 .16 .5 .32 .42$

Received July 14, 2021; Accepted October 29, 2021

\begin{abstract}
Subjective feelings feedbacks are commonly employed by a patient during forearm rehabilitation therapy without real-time data, leading to suboptimal recovery results in some patients. Technological innovations in the field of assisted rehabilitation have enabled the evolution of realtime monitoring systems. In this paper, interactive assistant development is presented as the interface to define the relationship between the kinematics patterns and the electromyographic signals during the forearm rehabilitation routine. Leap Motion (LM) and Shimmer3 EMG sensors read the routine behavior by following the movements that appear on the software. Real-time targets are programmed to lead the necessary forearm movements that the therapist sets to determine the recovery progress. The integration of software and hardware shows a dataset basis on interaction variables such as arm velocity, arm position, performance rate, and electrical muscle pulse. The results obtained from tests show that the system works effectively within a range of movement of 9 to 88 degrees in rotation about the axes, and velocities under $190 \mathrm{~mm} / \mathrm{s}$ show stable movement representation on software. Finally, the outcomes ranges show an alternative tool to evaluate patients with a forearm injury.
\end{abstract}

Subjective feelings, EMG, Data Set

\begin{abstract}
Resumen
Actualmente, retroalimentaciones subjetivas son comúnmente empleadas para evaluar pacientes con lesión de antebrazo, sin ofrecer datos en tiempo real, provocando resultados de recuperación no satisfactorios. Las innovaciones tecnológicas en rehabilitación asistida han evolucionado los sistemas de monitoreo en tiempo real. El artículo, presenta un asistente interactivo para evaluar la relación entre los patrones cinemáticos y las señales electromiografícas (EMG) presentes en movimientos de rehabilitación del antebrazo. Los sensores Leap Motion (LM) y Shimmer3 EMG leen el comportamiento del movimiento del antebrazo para seguir los objetivos programados en el software interactivo, los cuales son establecidos por el terapeuta para determinar el progreso de la recuperación. La integración de software y hardware, muestra un conjunto de datos basado en variables de interacción tales como: velocidad y posición del antebrazo, tasa de rendimiento y señales EMG. Los resultados obtenidos indican que el sistema puede funcionar eficazmente dentro de un rango de movimiento de 9 a 88 grados alrededor de los ejes de rotación, las velocidades por debajo de $190 \mathrm{~mm} / \mathrm{s}$ ofrecen una representación estable en el software de interacción. Finalmente, los rangos de operación permiten al asistente interactivo ser una herramienta alternativa en la evaluación de pacientes con lesión del antebrazo.
\end{abstract}

Asistente Interactivo, EMG, Patrones cinemáticos

Citation: JIMÉNEZ-GONZÁLEZ, Fernando C. \& TORRES-RAMÍREZ, Dulce Esperanza. Interactive assistant tool for the evaluation of kinematic patterns and EMG signals in patients with a forearm injury. Journal of Technological Engineering. 2021. 5-16: 32-42

\footnotetext{
* Correspondence to Author (e-mail: fernando_jimenez@utcj.edu.mx)

$\dagger$ Researcher contributing as first author.
} 


\section{Introduction}

Recent scientific evidence suggests to physicians and therapists in physical rehabilitation should be aware of the low rates of confidence in the subjective feedback of patients during the assessment of recovery or the assignment of high-impact rehabilitation routines (Van der Scheer, 2018). Modern technological development in physical patient rehabilitation assistants offers an objective data frame in injury evaluations related to arm, knee, hip, among others (Yandell, 2017), (Gupta, 2020), (Modi, 2020). Rehabilitation assistance systems are typically based on data capture devices, motion aids, and interactive software to evaluate patient therapy progress (Noveletto, 2018), (Van der Kuil, 2018). Data capture devices assist the quantification process of the movement routines evaluation (Yu, 2019). Variables of speed, acceleration, position, and strength are using as auxiliaries making decisions about the patient recovery process in exercise routines proposed by the professionals. Besides, some application systems use interactive guide software to manage the routine showing tangible benefits in rehabilitation process results (Alimanova, 2017).

Patients with forearm injury related to accidents such as stroke, fracture, or perforated wound (Se-Hun, 2019) require movement exercises as rehabilitation treatment assisted by a robotic person or rehabilitation device (Akdoğan, 2018). Kinematics variables such as velocity, position, acceleration, or even force quantify the performance related to radial deviation, flexion, and extension forearm exercises. The rehabilitation process usually takes a long period of time, especially when the professional therapists evaluate with clinical pain perception. From this point of view, the kinematics data set could be an auxiliary to improve the recovery process.

EMG signals are used to measure the electrical activity of muscles. Dividing muscles into sections is the most common way to extract features of the forearm electrical activity in flexion or extension movements. Moreover, the section division is useful to detect open-close movements of the hand (Jarque-Bou, 2019). Electrical activity in muscles shows a substantial difference in types of forearm movements.
Rehabilitation professionals use EMG signals to set perspective targets related to EMG response in exercise routines (Hedt, 2020).

In this paper, an interactive assistant tool is proposed as an evaluation alternative in forearm rehabilitation. The system links kinematics data to an interactive software developed in MATLAB, and EMG data is captured in parallel to describe the types of forearm movements. The main aim is to support evaluations reports of the recovery process providing quantify data from forearm performance in physical rehabilitation programs. Finally, an interactive game software complements the system with entertainment targets related to exercise routines programmed by therapists.

The rest of this paper is organized as follows. Section 2 presents related research. In Section 3, a description of the novel assistant tool is presented. Test results are presented in Section 4. Finally, Section 5 concludes the paper.

\section{Related work}

The literature evidence on devices and interfaces for motion recognition shows a trend in medical applications related to physical rehabilitation, elderly care, and physical conditioning of people. (Ignasiak ,2017), (Henriksen, 2018).

An interactive interface is typically used as a guide for developing movement routines with a medical intention of recovery. In addition, the development of interactive games prevents patients from getting bored or bothered by exercise routines. For example, Guneysu et al. (2018) presents an interactive rehabilitation process design based on the Celullo game with a set of tangible robots. The system guides the patient movement routine in a fun way, and the patient performs the routines at home. The design of the rehabilitation process is based on linking movements of the robot with forearm rehabilitation routine in the plane of the game. The results obtained in the ANOVA study show improvements in the performance of the arm movement in the exercise routine

The implementation of interactive games in maintenance therapy has had a boom in the treatment of Parkinson's disease. 
Fernández et al. (2019) presents a high level of satisfaction and compliance study based on integrating a signal acquisition device and non-invasive interactive games among patients with medium and moderate levels of the disease. The movement tests on the most affected side of the patient show a significant increase in skill coordination. However, more studies should be developed to verify signal acquisition device effectiveness.

Rotation joints detection is one of the main challenges to classify the movements of the forearm. Samad et al. (2017) presents a work based on a low-cost depth sensing device to find the rotation joint without markers through the angle measure of the elbow. The system classifies flexion and extension forearm movements by computing position vectors of the elbow. The results show the classified movements of five people according to the angle of rotation captured by the device.

Typically, EMG signals are the way to detect the starting impulse, which is defined as the electrical magnitude of the muscle when a force is applied. Pinzon et al. (2020) proposes a new hand movement recognition system, specially designed for signal processing, based on an EMG band capture device and filters processing as the mean square root and the Butterworth. The system is divided into two phases, the recognition of hand movements and the algorithm used to recognize muscle activity. Finally, the results show a satisfactory estimation of the muscular activity of four users without muscular injury.

Worldwide physical rehabilitation systems have evolved the way of evaluating recovery processes from physical injuries. Table 1 lists some of the works that have been performed on quantification movements systems. Each research project attempts to solve a specific problem in any part of the human body and uses different technologies, such as robotic systems, sensors, and interactive interfaces.

\begin{tabular}{|c|c|c|c|}
\hline Autor/year & Application & Signals & Interface \\
\hline $\begin{array}{l}\text { Jie et al. } \\
(2017)\end{array}$ & $\begin{array}{l}\text { Interactive } \\
\text { upper limb } \\
\text { rehabilitation } \\
\text { device in } \\
\text { elderly } \\
\text { patients who } \\
\text { have suffered } \\
\text { a stroke }\end{array}$ & $\begin{array}{l}\text { Force, } \\
\text { Rotation } \\
\text { angle }\end{array}$ & $\begin{array}{l}\text { Interactive } \\
\text { simulation } \\
\text { of daily } \\
\text { life } \\
\text { activity. }\end{array}$ \\
\hline $\begin{array}{l}\text { Dehem et } \\
\text { al. } \\
(2017)\end{array}$ & $\begin{array}{l}\text { Robotic assist } \\
\text { game } \\
\text { for motor and } \\
\text { cognitive } \\
\text { rehabilitation } \\
\text { after a } \\
\text { stroke }\end{array}$ & $\begin{array}{l}\text { Force, } \\
\text { Position }\end{array}$ & $\begin{array}{l}\text { Position } \\
\text { targets } \\
\text { with } \\
\text { distracting } \\
\text { elements }\end{array}$ \\
\hline $\begin{array}{l}\text { Lyu et al. } \\
\text { (2019) }\end{array}$ & $\begin{array}{l}\text { Development } \\
\text { of an } \\
\text { exoskeleton } \\
\text { for the knee, in } \\
\text { an interactive } \\
\text { game context }\end{array}$ & EMG & $\begin{array}{l}\text { Control } \\
\text { bird flight, } \\
\text { to avoid } \\
\text { obstacles, } \\
\text { the } \\
\text { stability of } \\
\text { the flight is } \\
\text { through } \\
\text { EMG } \\
\text { signals }\end{array}$ \\
\hline $\begin{array}{l}\text { Ghassemi } \text { et } \\
\text { al. } \\
(2019)\end{array}$ & $\begin{array}{l}\text { Development } \\
\text { of an } \\
\text { interactive } \\
\text { game control } \\
\text { through EMG } \\
\text { signals, using } \\
\text { the muscular } \\
\text { activity of the } \\
\text { hand. }\end{array}$ & EMG & $\begin{array}{l}\text { Interactive } \\
\text { scenarios } \\
\text { for } \\
\text { different } \\
\text { exercises, } \\
\text { such as } \\
\text { revealing } \\
\text { images, or } \\
\text { solving a } \\
\text { maze. }\end{array}$ \\
\hline $\begin{array}{l}\text { Daoud et al. } \\
(2020)\end{array}$ & $\begin{array}{l}\text { Rehabilitation } \\
\text { study of } \\
\text { patients with } \\
\text { cerebral palsy, } \\
\text { through a } \\
\text { depth sensing } \\
\text { device, which } \\
\text { identifies the } \\
\text { movements of } \\
\text { the right arm. }\end{array}$ & Position & $\begin{array}{l}\text { It is based } \\
\text { on } 3 \\
\text { interactive } \\
\text { games, } \\
\text { which } \\
\text { guide the } \\
\text { patient to } \\
\text { follow the } \\
\text { movement } \\
\text { routine. }\end{array}$ \\
\hline
\end{tabular}

Table 1 Related work of rehabilitation assistant developing

Assistants in physical rehabilitation systems face several developing obstacles. For example, the elderly could be unfamiliar with technological systems. Developing simple alternatives could be an auxiliary to improve the way an elder interacts with rehabilitation assistants. 
The literature review exposes some areas of opportunity that have not been explored at all, such as sensor fusion in interactive interfaces as a quantitative evaluation tool of the patients on the recovery process from a forearm injury. The present work shows an alternative sensor fusion tool of two capture sources (kinematic and EMG) that are contained through an interaction guide interface to evaluate the forearm movements in the three freedom degrees defined by Palma et al. (2021).

\section{Design proposal}

The interactive assistant tool is based on a multilevel operation design, using non-invasive realtime signal acquisition methods. The model is divided into four application levels: 1. Capture Device (Configuration and Calibration); 2. Targets programming in the interactive interface; 3. Real-time signal processing during routine; 4. Results of the work. Figure 1 shows the general scheme of the tool.

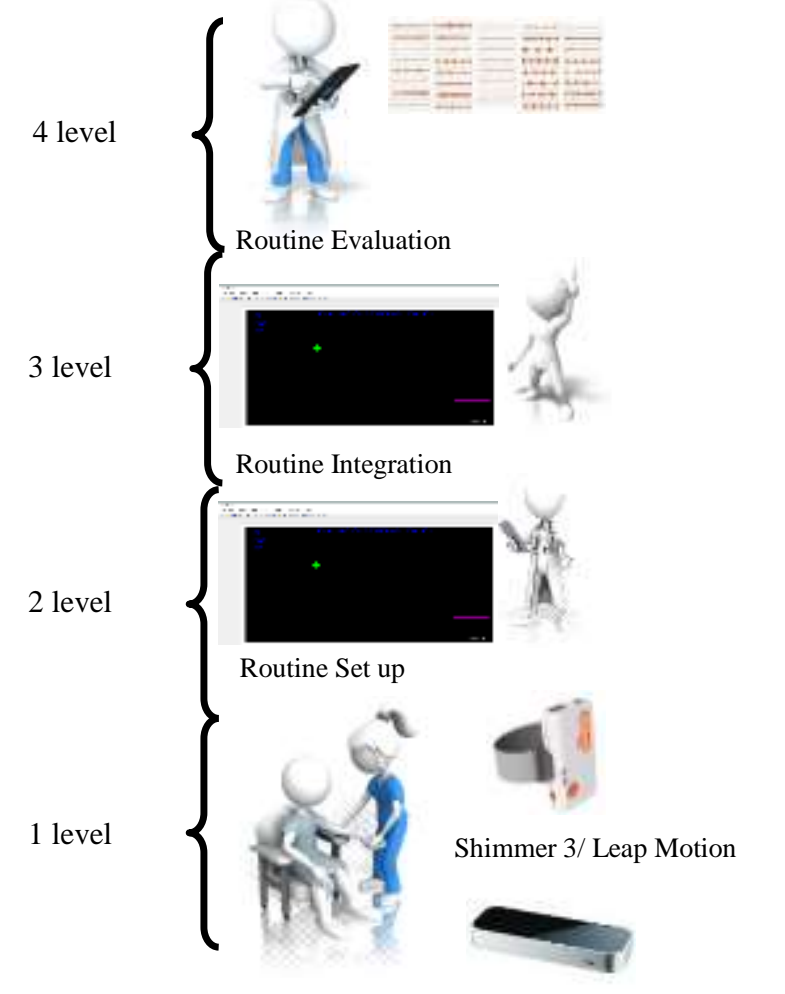

Figure 10 General schematic of the interactive assistant tool.

Each device is configured according to the individual specifications of the equipment, then the movement targets are programmed for the evaluation, which can be flexion, extension, supination, among others. The interface guides the patient in a fun interaction, where the kinematic variables and EMG are captured and processed.
Finally, the dataset of movements, positions, speeds, the electrical intensity of the muscle, and targets performance rate are presented as a result.

\subsection{Signal Acquisition}

The configuration and calibration of the acquisition devices are crucial to get objective evaluation results. The kinematic signals are obtained from Microsoft's Leap Motion (LM) device. The SDK package is used for communication and calibration with the interactive interface in the MATLAB programming environment. The anatomic structure connection of the hand and forearm allows obtaining the variables of position and speed of the forearm movements through the representation of the hand in real-time captured by the LM device. Figure 2 shows the relationship to capture kinematic signals.

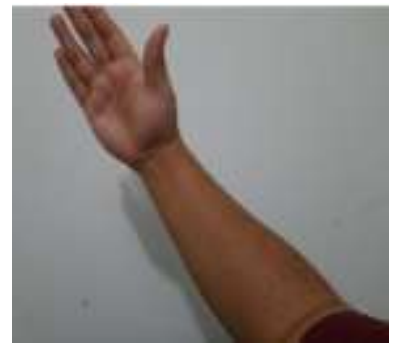

(a)

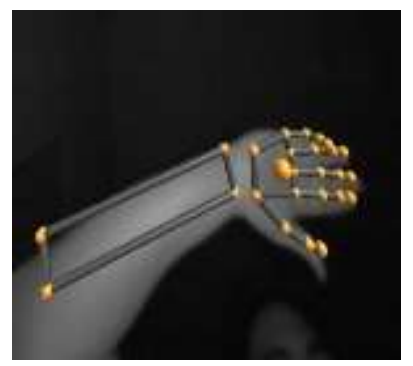

(c)

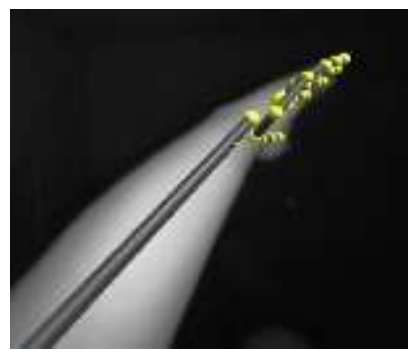

(b)

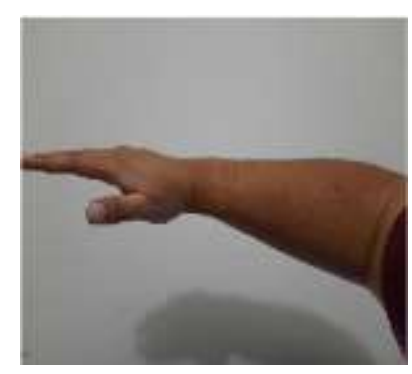

(d)
Figure 11 a) Extension; b) LM extension; c) LM flexion; d) Flexion

Figure 2 shows the orientation of the forearm through the LM device using the hand position. The patient should keep the hand orientation in the same direction as the forearm, it is important to avoid dropping or lifting the hand above the plane of the forearm. The ideal position to keep recognition stability is $250 \mathrm{~mm}$ above the sensor. (Vysocký, 2020). The acquisition of EMG signals was developed through a Shimmer 3 EMG device, which is a non-invasive device that wirelessly sends the electrical activity of the muscle through activation channels, even in muscular injured tissue. 
Typically, the range of EMG signal range operating frequencies is from $20 \mathrm{~Hz}$ to $500 \mathrm{~Hz}$ and the oscillation in voltage amplitudes is from $50 \mu \mathrm{V}$ to $5 \mathrm{mV}$ (González-Mendoza,2018). Vidar et al. (2021) recommends the preparation of the muscle areas where the capture electrodes will be positioned as a first step. Routine movements data are processed using a band-pass filter. The filtered data is analyzed employing statistical tools for subsequent presentation in the results of the interaction. Table 2 shows the position of the electrodes related to muscle and movement.

\begin{tabular}{|l|c|c|}
\hline \multicolumn{1}{|c}{ Muscle } & Movement Types & \multicolumn{1}{c|}{$\begin{array}{c}\text { Electrode } \\
\text { position }\end{array}$} \\
\hline Arm biceps & Internal Rotation & \\
\hline Arm biceps & Flexion - Extension & \\
\hline $\begin{array}{l}\text { Brachioradial } \\
\text { radius } \\
\text { of } \\
\text { the } \\
\text { extensor of }\end{array}$ & Supination & \\
\hline flexion/extension & \\
\hline
\end{tabular}

Table 2 Relationship of the electrode position for EMG signal capture

The red dots represent the electrodes, which capture the electrical pulses from the muscle, while the blue dot represents the reference. It is crucial to clean impurities from the skin to reduce the impedance effect of the human body. The data will be received wirelessly through Wi-Fi for further analysis.

\subsection{Software Interface}

The proposed interface development uses a virtual entertainment environment to increase patient interest.
The patient should follow a virtual ball movement to hit it with a bar in a specific position and area.

The movement bar helps the patient performing the correct forearm exercises to score points. The patient gets rewards points by hitting the virtual ball in the specific orientation proposed by the therapist. The interface was developed in the MATLAB environment. The position and orientation of the hitting bar are associated with the LM device information. Figure 3 shows an example of using the bar orientation to perform the flexion-extension movement during a game therapy session.

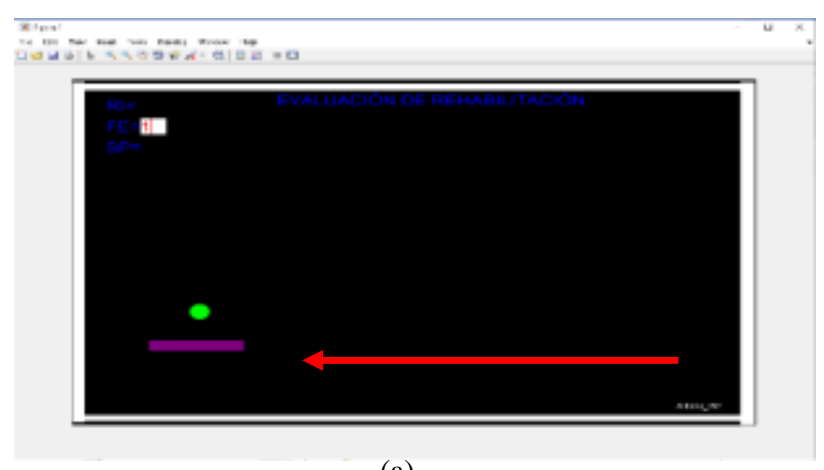

(a)

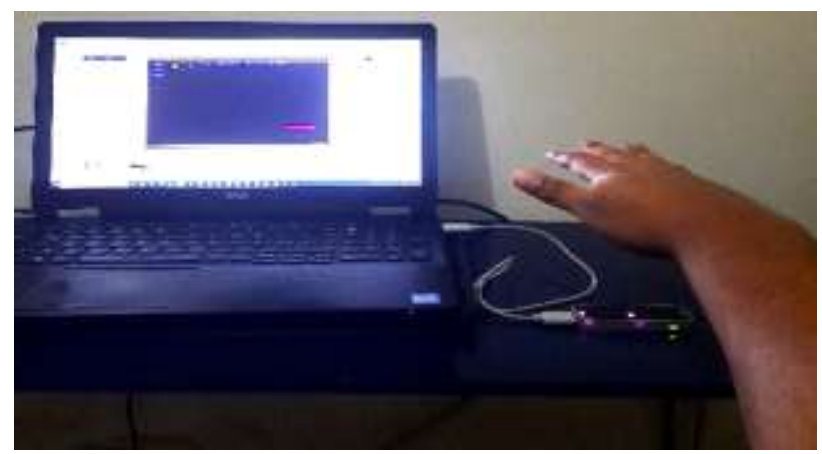

(b)

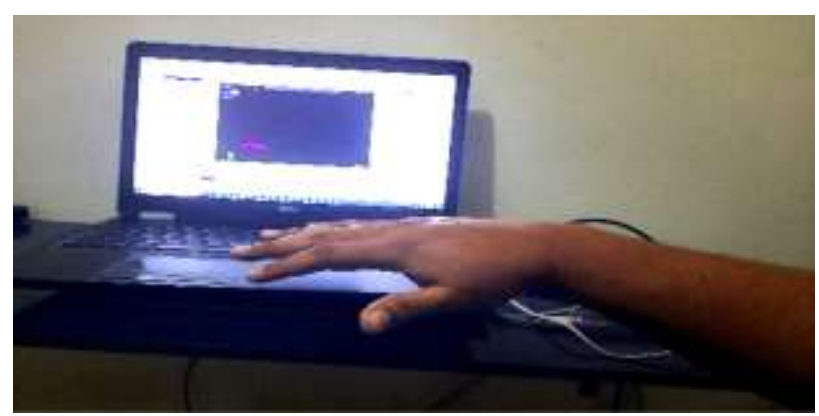

(c)

Figure 12 Interaction interface screen with flexion motion. a: Interface; b: Initial position; c: End position.

The patient hits the virtual ball with the flexion movement from the initial point to the final point. A new target appears when the patient hits the ball restarting the operation. Then the patient should extend the forearm to the initial position to begin a correct movement.

JIMÉNEZ-GONZÁLEZ, Fernando C. \& TORRES-RAMÍREZ, Dulce Esperanza. Interactive assistant tool for the evaluation of kinematic patterns and EMG signals in patients with a forearm injury. Journal of Technological Engineering. 2021 
The exercise ends when the patient reaches the number of flexions and extensions proposed by the therapist or fails two times hitting the ball.

A failure is determined when the ball exceeds the horizontal or vertical plane of the bar, depending on the exercise. The number of failures was set at two per exercise.

In the beginning, the rehabilitation professional must select the forearm to be exercised (right or left), the types of movements (internal rotation, flexion, extension, supination), and the number of times movements to repeat during the exercise. Besides, the registry saves the personal data of the patient. The software uses the data entered by the professional to create the different instances of the virtual ball and the orientation of the hit bar. Hit bar appears at each turn of the interface, depending on the type of exercise. The setting section is an interface that was created using the MATLAB package (GUI) tool to support the professionals to set the routine. Figure 4. Shows the setting screen of the interface.

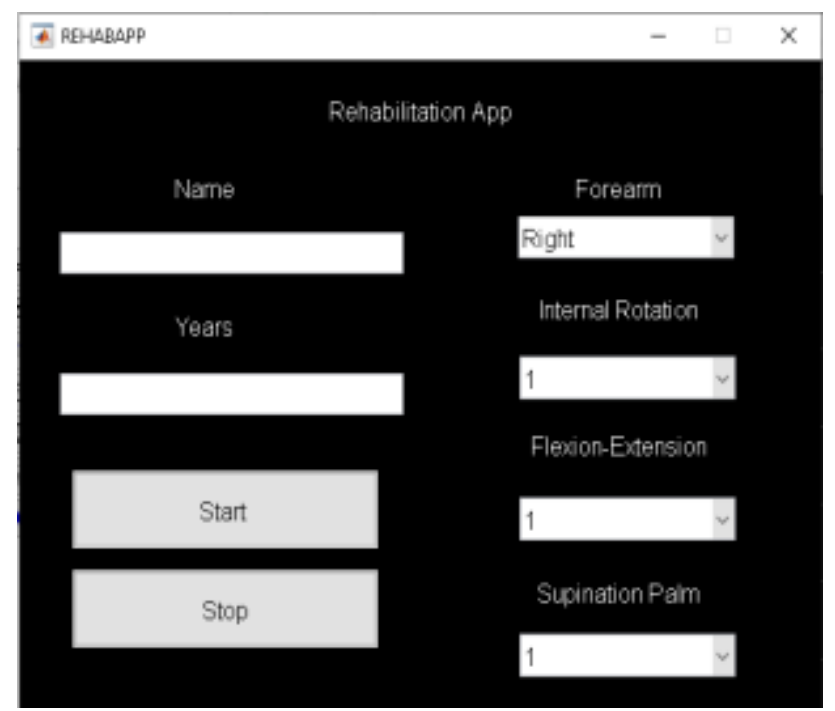

Figure 13 Setting window interface

The motion programming selection determines the direction of the bar. For example, an internal rotation computes the rotation matrix to represent it in the screen in the correct position then the user could hit the ball to get the right points. Equation 1 shows the matrix used to determine the direction of the bar with lengths in pixels.

$\begin{aligned} & p_{x} \\ & p_{y}\end{aligned}=\left(\begin{array}{cc}\cos \theta & -\sin \theta \\ \sin \theta & \cos \theta\end{array}\right)\left(\begin{array}{l}l_{p x} \\ l_{p y}\end{array}\right)$
Where $p_{x}, p_{y}$, are the final vector position in pixels, $\theta$, is the internal rotation angle that the patient should emulate, and $l_{p x}, l_{p y}$ are the fixed lengths of the hit bar in pixels.

Figure 5 shows the display of the associated internal rotational motion for the rebound of the virtual ball. Finally, the game view changes to vertical to obtain points at different degrees in the internal rotation exercise.
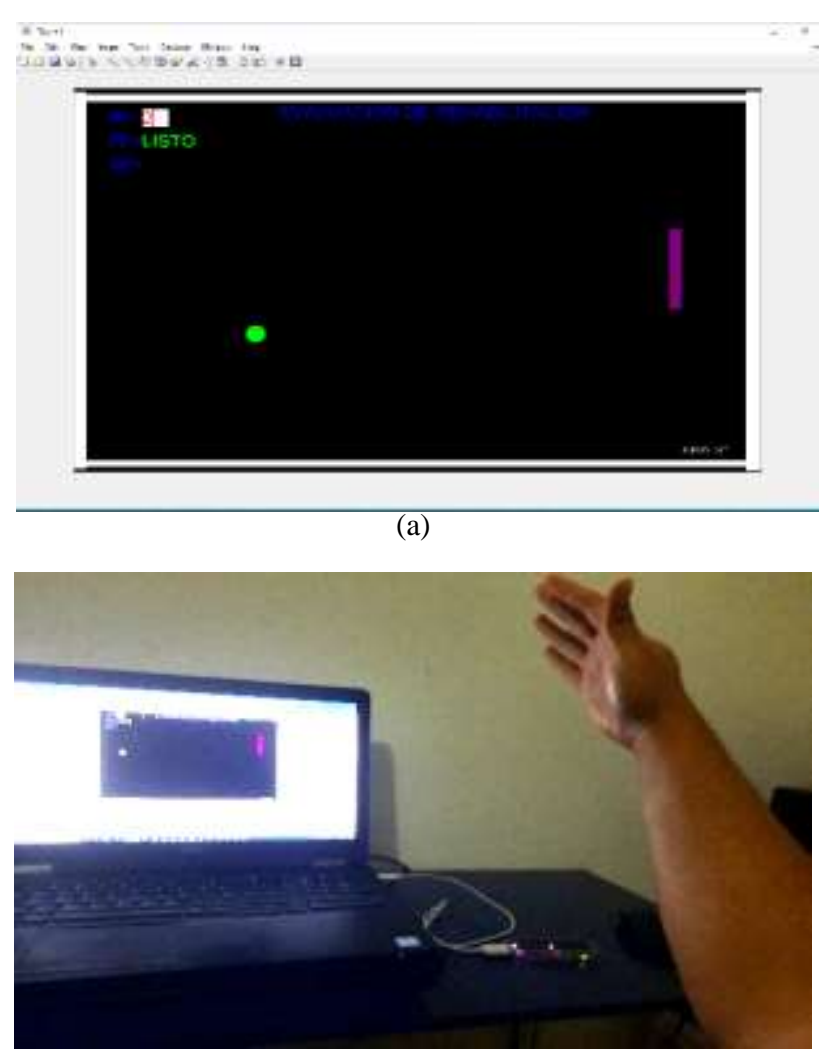

(b)

Figure 14 Internal rotation movement. a: Interface; b: Direction of the forearm

Other essential exercises are supination and palm orientation, in which the horizontal bar rotates 360 degrees and the ball is on the opposite side from the current palm location. Besides, time is monitored while the patient moves the forearm to the correct direction under the virtual ball as sufficient evidence of supination. Figure 6 shows an extract of the horizontally moving point algorithm. 


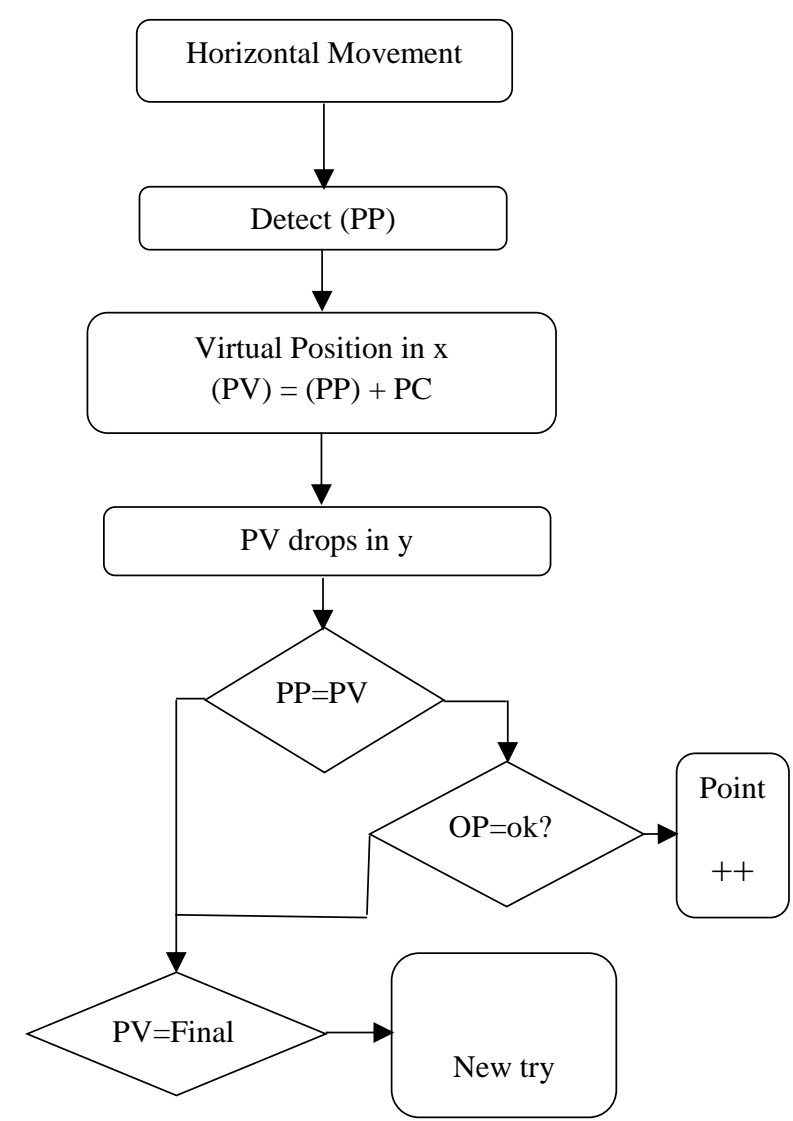

Figure 15 Horizontal movement. Palm position (PP), Virtual Ball Position (PV), Opposite Constant position (PC), Palm direction (OP)

During the exercise, the patient faces several shifts, where the virtual ball will appear at different points of the virtual environment, with distinct kinematic movement challenges. As an alternative, ConsensysPro Software captures the EMG signals results of the shift interaction present in each movement. Finally, MATLAB statistical tools process the EMG signals and characterize the movements in voltage amplitude (mv). Figure 7 shows the interaction of the Shimmer3 EMG sensor with the gaming interface.

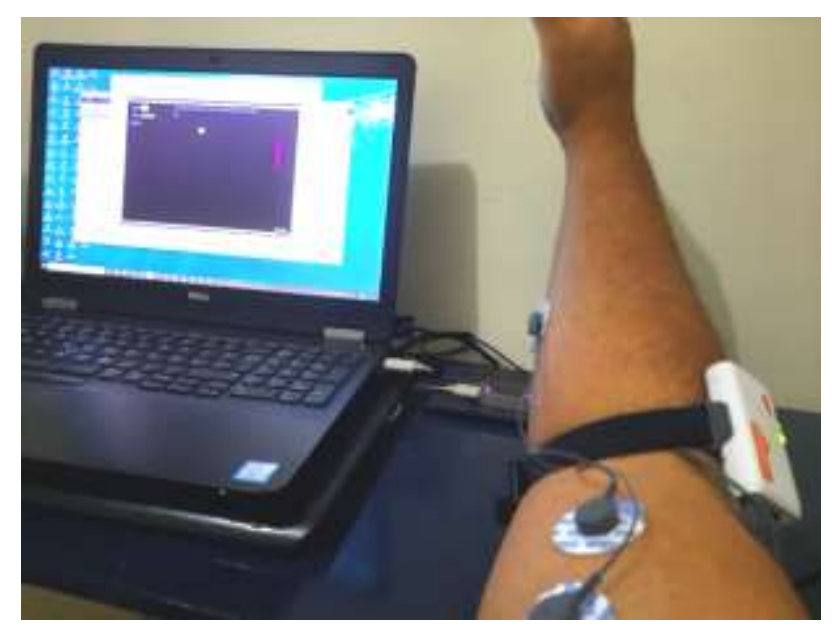

Figure 16 Shimmer3 EMG sensor interface

\subsection{Routine Evaluation}

When the user completes the interactive exercises, the interface presents the data set in kinematic variables, targets achieved, and EMG signal ranges. Table 3 shows the output configuration array associated with patient performance in the kinematic model.

\begin{tabular}{|l|l|l|}
\multicolumn{1}{|c}{$\begin{array}{c}\text { Movement } \\
\text { velocity }\end{array}$} & \multicolumn{1}{c|}{$\begin{array}{c}\text { Rotation } \\
\text { angle } \mathbf{x}\end{array}$} & \multicolumn{1}{c|}{$\begin{array}{c}\text { Rotation } \\
\text { angle } \mathbf{y}\end{array}$} \\
\hline Mean & Max & Max \\
\hline Max & Min & Min \\
\hline
\end{tabular}

Table 3 Kinematics Dataset Structure

For the evaluation of the targets, the interface compares the planned targets with the satisfactory ones. A satisfactory target is when the patient hits the virtual ball with the right orientation and position. Table 4 shows the output configuration array associated with the performance of achieved targets.

\begin{tabular}{|l|l|l|}
\multicolumn{1}{|c}{$\begin{array}{c}\text { M. Internal } \\
\text { Rotation }\end{array}$} & \multicolumn{1}{c}{$\begin{array}{c}\text { M. Flexion } \\
\text { and extension }\end{array}$} & \multicolumn{1}{c|}{$\begin{array}{c}\text { M. Supination } \\
\text { and palm }\end{array}$} \\
\hline M. Planned & M. Planned & M. Planned \\
\hline M. Achieved & M. Achieved & M. Achieved \\
\hline \% Satisfactory & \% Satisfactory & \% Satisfactory \\
\hline
\end{tabular}

Table 4 Performance Dataset Structure

For EMG signals associated with interactive exercises, the system uses the maximum and minimum voltage amplitude to classify the results of the movements. For example, when the user performs three flexion movements, the system computes maximum and minimum mean values in mv. Table 5 shows the output configuration array associated with the EMG performance of achieved targets.

\begin{tabular}{|l|l|l|}
\hline \multicolumn{1}{|c|}{ Movement Max } & \multicolumn{1}{c|}{ Min } \\
\hline Internal Rotation & Mean Max & Mean Min \\
\hline $\begin{array}{l}\text { Flexion and } \\
\text { extension }\end{array}$ & Mean Max & Mean Min \\
\hline $\begin{array}{l}\text { Supination and } \\
\text { palm }\end{array}$ & Mean Max & Mean Min \\
\hline
\end{tabular}

\section{Table 5 EMG Dataset Structure}

The results screen displays the final score performance helping the therapist with a quantitative exercise routine evaluation. Figure 8 shows the session results screen. 
Ziquat

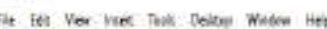

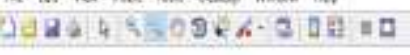

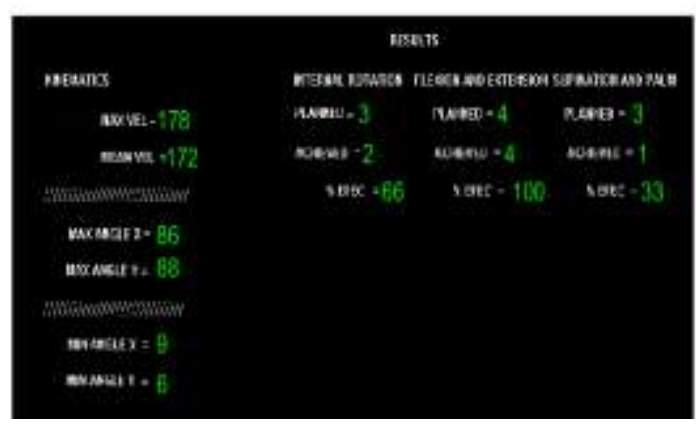

Figure 17 Final Results Screen

\section{Results}

Several experiments were developed to find the operating parameters of the assistant tool. At the first level, it is important to determine the operating range of the LM device interacting with the interface. Two tests were designed to evaluate the repeatability and reproducibility indices of the representation of the hit bar with respect to the patient hand position. Horizontal and vertical marks were used to define the limits of the flexion, extension, and internal rotation movements.

Twenty-seven horizontal and vertical movements were performed, divided into three healthy patients, and three different position marks at $0^{\circ}, 45^{\circ}, 90^{\circ}$. The dataset is the achieved positions from the patients. The device repeatability results are shown in Figure 9, grouped by test type.
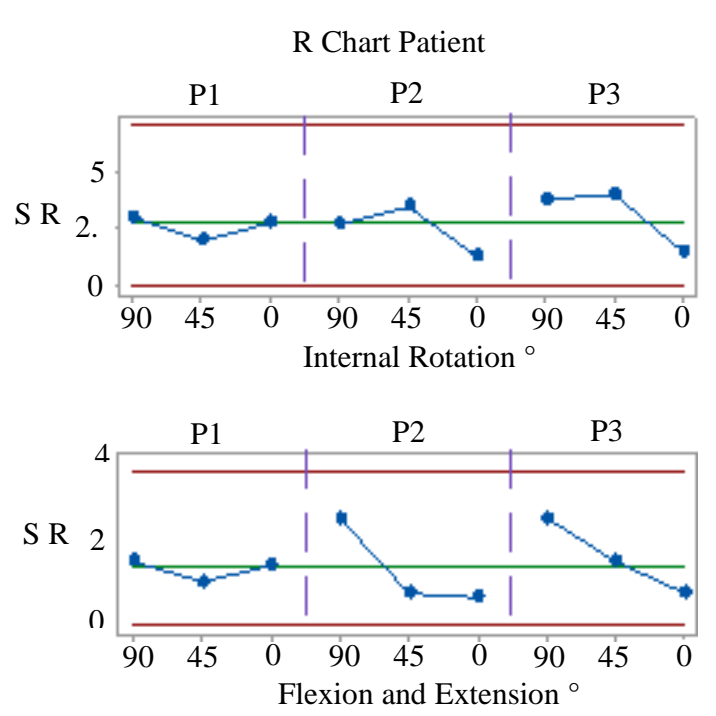

Patient Performance
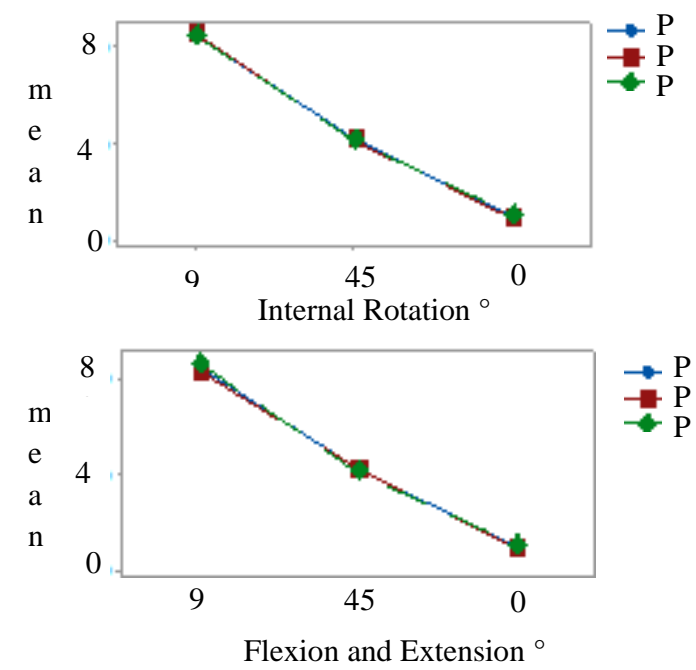

Figure 18 Repeatability studies by movement type

In the results, the repeatability of the flexion-extension and internal rotation movements is about $3 \%$ and $4 \%$, respectively, which gives reliability that the device and interface are capable of providing correct data on the location of the forearm in response to the movement of the patient.

The maximum limit operating speed is $190 \mathrm{~mm} / \mathrm{s}$. The repeatability reduces the performances with values above the max limit. The minimum flexion-extension and internal rotation range that the device and interface detect are 9 to 88 degrees maximum. Five healthy patient sessions were used to compute the operating ranges at a minimum distance of Dx_min $=100 \mathrm{~mm}$, and Dy_min $=180 \mathrm{~mm}$ above the LM, for the start of the session. Figure 10. Shows the ideal initial position for interacting with the interface. 


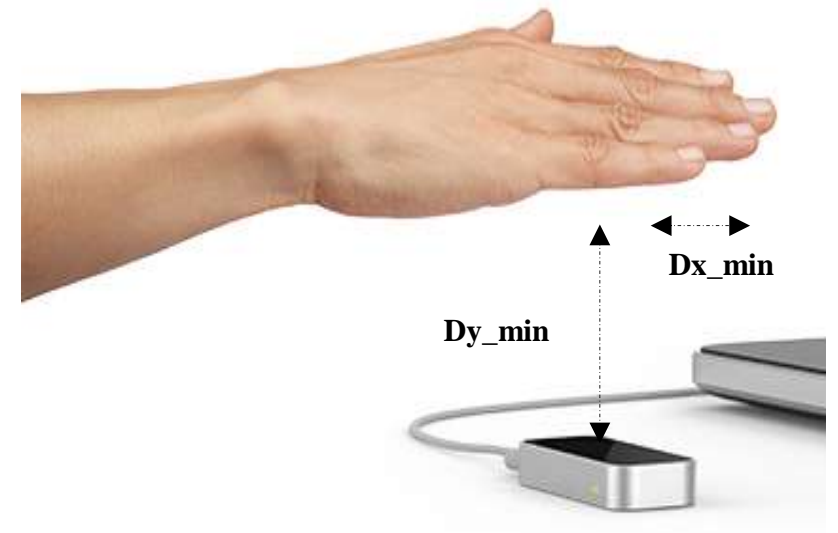

Figure 19 Position (x,y), start position of the session

Testing of the Shimmer 3 EMG device was based on establishing the maximum and minimum ranges of voltage amplitude for the different types of movements related to the performance of the patient in the routine session. Twenty samples of five distinct movements were taken to test the EMG signals. Figure 11 shows the minimum and maximum results of five types of movements presented in the interface.

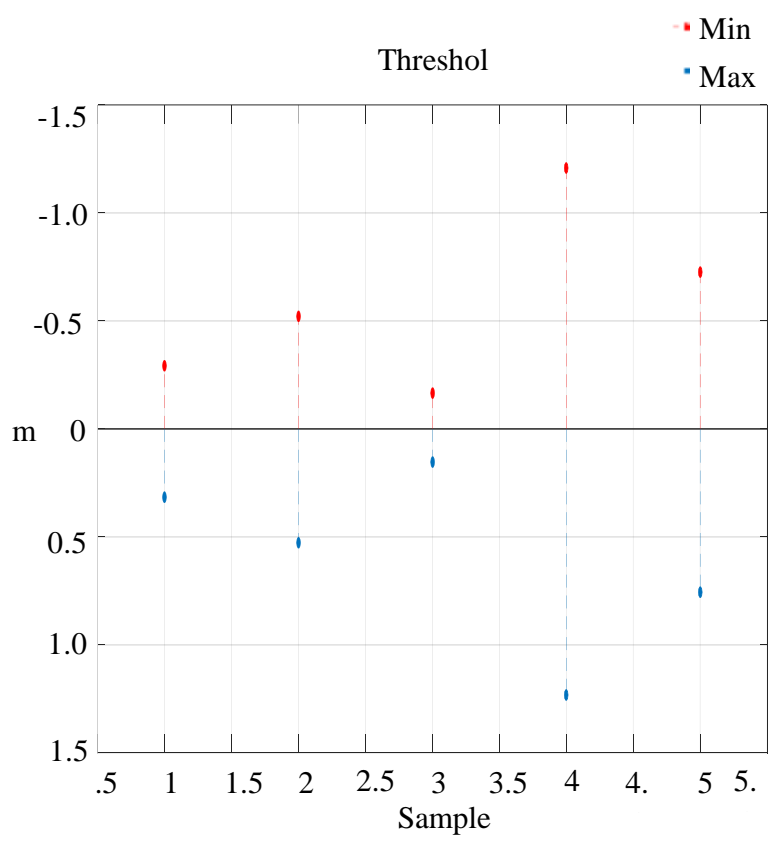

Figure 20 Voltage amplitude. Maximums and minimums per movement

There is a difference in the threshold voltage magnitude between patient movements in the results. Each movement is classified by the EMG signals values in the routine. In full session results, five test subjects developed a session of interaction with the interface, presenting quantitative results in velocities, positions, and EMG signals.
Besides, achievement target evaluation is presented. Table 6 shows some of the results of the full sessions.

\begin{tabular}{|l|r|r|r|r|}
\hline Patient & \multicolumn{1}{c}{ Max Vel } & \% IR & \% FE & \% REMG \\
\hline 1 & $172 \mathrm{~mm} / \mathrm{s}$ & 92 & 100 & 90 \\
\hline 2 & $178 \mathrm{~mm} / \mathrm{s}$ & 95 & 100 & 92 \\
\hline 3 & $189 \mathrm{~mm} / \mathrm{s}$ & 98 & 100 & 95 \\
\hline 4 & $170 \mathrm{~mm} / \mathrm{s}$ & 95 & 90 & 92 \\
\hline 5 & $180 \mathrm{~mm} / \mathrm{s}$ & 100 & 100 & 95 \\
\hline
\end{tabular}

Table 6 Full session results: IR Internal Rotation, FE Flexion Extension, REMG Relation with EMG signals

\section{Conclusions}

In this paper, an interactive assistant tool was presented as an evaluation alternative to capture quantitative variables of patients with a forearm injury. Sometimes rehabilitation routines could be boring or bothering for the patient, so the work intends to offer an entertaining alternative to the patient when performing the rehabilitation routine or evaluation. In addition, a reliable data set is providing related to variables from forearm movements.

In conclusion, the improvements presented by the interactive tool to monitor the recovery process are:

\section{- Clinical diagnosis support by quantitative evaluation reports in the forearm recovery process. \\ - $\quad$ The patient develops exercises therapy through the programming routines proposed by professionals in an entertainment environment. \\ - Sensor fusion of multiple variables (kinematics and EMG) defines the forearm movements to monitor the recovery progress.}

Finally, the project begins as an academic-technological development in the area of assisted physical rehabilitation. However, the project evolved until it produced an application for medical services. The operation ranges allow the interactive tool to be an alternative application in the evaluation processes of forearm injuries. In future works, the development of a driver to include both signals in the same game interface is the target, as well as to deploy Artificial Intelligent models to define automatic exercise routines. 


\section{References}

Akdoğan, E., Aktan, M. E., Koru, A. T., Arslan, M. S., Atlihan, M., \& Kuran, B. (2018). Hybrid impedance control of a robot manipulator for wrist and forearm rehabilitation: Performance analysis and clinical results. Mechatronics, 49, 77-91.

Alimanova, M., Borambayeva, S., Kozhamzharova, D., Kurmangaiyeva, N., Ospanova, D., Tyulepberdinova, G., ... \& Kassenkhan, A. (2017, April). Gamification of hand rehabilitation process using virtual reality tools: Using leap motion for hand rehabilitation. In 2017 First IEEE International Conference on Robotic Computing (IRC) (pp. 336-339). IEEE.

Andersen, V., Pedersen, H., Steiro Fimland, M., Peter Shaw, M., Jorung Solstad, T. E., Stien, N. ... \& Hole Saeterbakken, A. (2021). Efectos Agudos de las Bandas Elásticas como Resistencia o Asistencia sobre la EMG, la Cinética y la Cinemática durante el Peso Muerto en Hombres Entrenados en Fuerza-Ciencias del Ejercicio. Revista de Educación Física, 1(1).

Daoud, M. I., Alhusseini, A., Ali, M. Z., \& Alazrai, R. (2020). A Game-Based Rehabilitation System for Upper-Limb Cerebral Palsy: A Feasibility Study. Sensors, 20(8), 2416.

Fernández-González, P., Carratalá-Tejada, M., Monge-Pereira, E., Collado-Vázquez, S., Baeza, P. S. H., Cuesta-Gómez, A., ... \& Cano-de la Cuerda, R. (2019). Leap motion-controlled video game-based therapy for upper limb rehabilitation in patients with Parkinson's disease: a feasibility study. Journal of neuroengineering and rehabilitation, 16(1), 1-10.

Ghassemi, M., Triandafilou, K., Barry, A., Stoykov, M. E., Roth, E., Mussa-Ivaldi, F. A., .. \& Ranganathan, R. (2019). Development of an EMG-controlled serious game for rehabilitation. IEEE Transactions on Neural Systems and Rehabilitation Engineering, 27(2), 283-292.

González-Mendoza, A., Pérez-SanPablo, A. I., López-Gutiérrez, R., \& Quiñones-Urióstegui, I. (2018, September). Validation of an EMG sensor for Internet of Things and Robotics. In 2018 15th International Conference on Electrical Engineering, Computing Science and Automatic Control (CCE) (pp. 1-5). IEEE.
Guneysu Ozgur, A., Wessel, M. J., Johal, W., Sharma, K., Özgür, A., Vuadens, P., .. \& Dillenbourg, P. (2018, February). Iterative design of an upper limb rehabilitation game with tangible robots. In Proceedings of the 2018 ACM/IEEE International Conference on Human-Robot Interaction (pp. 241-250).

Gupta, A., Singh, A., Verma, V., Mondal, A. K., \& Gupta, M. K. (2020). Developments and clinical evaluations of robotic exoskeleton technology for human upper-limb rehabilitation. Advanced Robotics, 34(15), 1023-1040.

Hedt, C., Lambert, B. S., Daum, J., Pearson, J. M., \& McCulloch, P. C. (2020). Forearm position matters during eccentric shoulder exercises: an EMG recruitment study with implications for rehabilitation. International Journal of Sports Physical Therapy, 15(6), 1110.

Heins, S., Dehem, S., Montedoro, V., Dehez, B., Edwards, M., Stoquart, G., ... \& Lejeune, T. (2017, April). Robotic-assisted serious game for motor and cognitive post-stroke rehabilitation. In 2017 IEEE 5th International Conference on Serious Games and Applications for Health (SeGAH) (pp. 1-8). IEEE.

Henriksen, A., Mikalsen, M. H., Woldaregay, A. Z., Muzny, M., Hartvigsen, G., Hopstock, L. A., \& Grimsgaard, S. (2018). Using fitness trackers and smartwatches to measure physical activity in research: analysis of consumer wrist-worn wearables. Journal of medical Internet research, 20(3), e110.

Ignasiak, D., Rüeger, A., \& Ferguson, S. J. (2017). Multi-segmental thoracic spine kinematics measured dynamically in the young and elderly during flexion. Human movement science, 54, 230-239.

Jarque-Bou, N. J., Vergara, M., Sancho-Bru, J. L., Gracia-Ibáñez, V., \& Roda-Sales, A. (2019). A calibrated database of kinematics and EMG of the forearm and hand during activities of daily living. Scientific data, 6(1), 1-11.

Jie, S., Haoyong, Y., Chaw, T. L., Chiang, C. C., \& Vijayavenkataraman, S. (2017). An interactive upper limb rehab device for elderly stroke patients. Procedia CIRP, 60, 488-493. 
Lyu, M., Chen, W. H., Ding, X., Wang, J., Pei, Z., \& Zhang, B. (2019). Development of an EMG-controlled knee exoskeleton to assist home rehabilitation in a game context. Frontiers in neurorobotics, 13, 67.

Modi, N., \& Singh, J. (2020). A survey of research trends in assistive technologies using information modelling techniques. Disability and Rehabilitation: Assistive Technology, 1-19.

Noveletto, F., Soares, A. V., Mello, B. A., Sevegnani, C. N., Eichinger, F. L. F., Hounsell, M. D. S., \& Bertemes-Filho, P. (2018). Biomedical serious game system for balance rehabilitation of hemiparetic stroke patients. IEEE Transactions on Neural Systems and Rehabilitation Engineering, 26(11), 2179-2188.

Palma, F. H., Cifre, M. J., Mancilla, I. C., FloresLeón, A., \& Guzmán-Venegas, R. (2021). Activación de los músculos escapulohumerales superficiales en tres planos distintos de elevación del hombro. Journal of Movement \& Health, 18(2).

Park, S. H., Yi, J., Kim, D., Lee, Y., Koo, H. S., \& Park, Y. L. (2019, April). A lightweight, soft wearable sleeve for rehabilitation of forearm pronation and supination. In 2019 2nd IEEE International Conference on Soft Robotics (RoboSoft) (pp. 636-641). IEEE.

Pinzón-Arenas, J. O., Jiménez-Moreno, R., \& Rubiano, A. (2020). Percentage estimation of muscular activity of the forearm by means of EMG signals based on the gesture recognized using CNN. Sensing and Bio-Sensing Research, 29, 100353.

Samad, R., Bakar, M. Z. A., Pebrianti, D., Mustafa, M., \& Abdullah, N. R. H. (2017). Elbow Flexion and Extension Rehabilitation Exercise System Using Marker-less Kinectbased Method. International Journal of Electrical \& Computer Engineering (2088-8708), 7(3).

Van der Kuil, M. N., Visser-Meily, J., Evers, A. W., \& Van der Ham, I. J. (2018). A usability study of a serious game in cognitive rehabilitation: a compensatory navigation training in acquired brain injury patients. Frontiers in psychology, 9, 846.
Van der Scheer, J. W., Hutchinson, M. J., Paulson, T., Ginis, K. A. M., \& Goosey-Tolfrey, V. L. (2018). Reliability and validity of subjective measures of aerobic intensity in adults with spinal cord injury: a systematic review. PM\&R, 10(2), 194-207.

Vysocký, A., Grushko, S., Oščádal, P., Kot, T., Babjak, J., Jánoš, R., ... \& Bobovský, Z. (2020). Analysis of Precision and Stability of Hand Tracking with Leap Motion Sensor. Sensors, 20(15), 4088.

Yandell, M. B., Quinlivan, B. T., Popov, D., Walsh, C., \& Zelik, K. E. (2017). Physical interface dynamics alter how robotic exosuits augment human movement: implications for optimizing wearable assistive devices. Journal of neuroengineering and rehabilitation, 14(1), 1-11.

Yu, X., \& Xiong, S. (2019). A dynamic time warping based algorithm to evaluate kinectenabled home-based physical rehabilitation exercises for older people. Sensors, 19(13), 2882. 